\title{
FUZZY SETS AND FUZZY LOGIC IN MULTI-CRITERIA DECISION MAKING. THE 50TH ANNIVERSARY OF PROF. LOTFI ZADEH'S THEORY: INTRODUCTION
}

\author{
Enrique HERRERA-VIEDMA \\ Department of Computer Science and Artificial Intelligence, University of Granada, \\ 18071 Granada, Spain
}

\section{Acknowledgements}

First of all, we would like to thank all the authors for their contributions to this special issue and help in showing the usefulness of fuzzy technologies in Multi-Criteria Decision Making. Then, we would like to thank all the reviewers who have collaborated with us to guarantee the quality of this special issue. Finally, thanks to Edmundas Kazimieras Zavadskas, the TEDE Editor in Chief, for proposing the preparation of this special issue and inviting me to write this introduction to the special issue and continuous encouragement and support.

\section{Fuzzy sets and fuzzy logic: applications}

Fuzzy sets were introduced by the Prof. Lotfi A. Zadeh in 1965 as an extension of the classical notion of set (Zadeh 1965). In classical set theory a set of elements is a crisp set because an element only has two membership possibilities, an element either belongs or does not belong to the set. However, fuzzy sets are sets whose elements are characterized by membership degrees represented with the aid of a membership function valued in the real unit interval $[0,1], 0$ being the minimum degree of membership, 1 the maximum degree of membership, and the other values in $[0,1]$ representing different degrees of membership. Fuzzy Sets Theory provides mathematical foundations to treat imprecision, inexactness, ambiguity, and uncertainty that appear in real problems (Dubois, Prade 1988).

Fuzzy logic is an extension of the Boolean logic which is based on the Fuzzy Sets Theory. By introducing the notion of degree in the verification of a condition in a rule system, 
fuzzy logic provides a very valuable flexibility for reasoning, which makes it possible to take into account inaccuracies and uncertainties associated to the human reasoning. Furthermore, using the important fuzzy concept of linguistic variable (Zadeh 1975a, 1975b, 1975c) fuzzy logic allows to formalize human reasoning in such a way that the rules are set in natural language. Thus, Zadeh introduced the concepts of fuzzy set and fuzzy logic in order to provide a tool for representing and reasoning in a manner similar to the way humans express knowledge, make decisions and summarize data (Kacprzyk, Pedrycz 2015).

Since its appearance in 1965, fuzzy techniques have been the target of much criticism, but the strength of the fuzzy scientific community and the quality of achieved results and developments have driven its growth. Today, the research on fuzzy logic holds a leading position in international panorama of science as it is shown by the major conferences such as FUZZ-IEEE, IFSA, IPMU; important journals such as IEEE Trans. On Fuzzy Systems, Fuzzy Sets and Systems, Journal of Intelligent \& Fuzzy Systems, Fuzzy Optimization and Decision Making; and leading scientists such as Didier Dubois, Ronald Yager, Witold Pedrycz, Francisco Herrera, Janusz Kacprzyk, Jerry Mendel, Enric Trillas.

Fuzzy sets theory and fuzzy logic are important technologies that constitute the area of computational intelligence, together with other technologies as rough sets theory, evolutionary computation and neural networks. Therefore, computational intelligence tools identify a set of nature-inspired computational methodologies to address real-world problems that are not solved satisfactorily by traditional approaches. Fuzzy sets and fuzzy logic play a leading role inside computational intelligence tools because, as aforementioned, it allows us to deal effectively with uncertainty that is common in human reasoning. In the literature we can find important applications of fuzzy tools in research areas such as Decision Theory, Management Science, Operations Research, Politics, Social Psychology, Economics, Engineering (Buckley et al. 2002; Kaufmann, Gupta 1988; Klir, Yuan 1995). Also to develop fuzzy intelligent systems for information retrieval, recommender systems, relational database, web quality, digital libraries, control systems, data mining, autonomous robots (Herrera-Viedma et al. 2006; Kacprzyk, Pedrycz 2015; Yager, Zadeh 1992). Some important fuzzy tools to solve problems are (Dubois, Prade 1988; Kacprzyk, Pedrycz 2015): fuzzy connectives, fuzzy implications, aggregation functions, fuzzy integrals, type-2 fuzzy sets, linguistic variables, interval-valued fuzzy sets, intuitionistic fuzzy sets, fuzzy numbers, fuzzy preference relations, fuzzy ontology, fuzzy rule-based systems, and fuzzy clustering.

\section{Fuzzy approaches in multi-criteria decision making}

Multi-Criteria Decision Making (MCDM) was introduced as a promising and important field of study in the early 1970'es. Its aim is to help decision makers solve complex decision problems in a systematic, consistent and more productive way (Carlsson, Fuller 1996). MCDM is concerned with structuring and solving decision and planning problems involving multiple criteria in order to support the complex decision making processes that human beings develop in their daily lives. In MCDM problems there are not only very complex issues involving multiple criteria, but there are also multiple parties who could 
be deeply affected from the consequences. According to Carlsson and Fuller (1996) we can identify four major families of methods in MCDM: i) the outranking approach whose most important MCDM methods are ELECTRE (Roy 1968) and Promethee (Brans, Vincke 1985); ii) value and utility theory approaches (Fishburn 1970; Keeney, Raiffa 1976), being an important MCDM method the Analytic Hierarchy Process (AHP) developed by Thomas L. Saaty (1980); iii) the interactive multiple objective programming approach (Yu 1973; Zeleny 1973), and iv) group decision, consensus and negotiation theory (Lehrer, Wagner 1981; Zartman 1978).

Many decision situations usually involve imprecise, uncertain, indefinite and subjective data that are difficult to represent and manage. When the decision situations involve experts the complexity of the decision process could be complicated because they could present a limited information, different formats of preference modelling, different domains to express their preferences (linguistic or numerical). Sometimes, even it could appear dynamic parameters that cause the decision making process to become more complex and challengeable. Fuzzy tools have shown to be usefulness to model and deal with such problematic. The first fuzzy approach in decision making was introduced by Bellman and Zadeh (1970). Since then many other fuzzy approaches have been defined for each of the four families of MCDM methods listed above (Delgado et al. 1994; Fodor, Roubens 1994; Kacprzyk et al. 1997; Zimmermann 1987).

Fuzzy MCDM methods offer multiple ways to model and manage problems and variables that are difficult to quantify in Economics. In fuzzy MCDM methods it is possible to exploit the potential of fuzzy techniques to handle uncertain information in the processes of decision making (Buckley et al. 2002; Zopounidis et al. 2001). However, there exist many challenges in Economics in order to understand the complex behavior of the customers and producers and formulate recommendations and methods that can be used by both, managers and customers, to optimize their decisions. Some of these challenges are:

- The management of incomplete or missing information (Alonso et al. 2008; Ureña et al. 2015).

- How to represent complex linguistic expressions in group decision making (Massanet et al. 2014; Morente-Molinera et al. 2015).

- The management of dynamic parameters in decision making (Pérez et al. 2010).

- The introduction of new negotiation measures to guide the consensus processes in contexts Web 2.0. (Alonso et al. 2013; Cabrerizo et al. 2010, 2015; Pérez et al. 2014).

- The management of the trust among experts in group decision making (Wu et al. 2015).

\section{About the papers of this special issue}

Let us now briefly summarize the content of each paper from this special issue, which is composed of eight new contributions on the development of fuzzy models for MCDM, as well as formal fuzzy MCDM approaches applied in real practical problems. Accordingly, the submissions can be split into three groups. 
The first one includes two papers presenting novel fuzzy MCDM models developed using significant aggregation operators. The second group includes two papers introducing new fuzzy MCDM models for heterogeneous decision contexts. The third group covers four real-life applications of fuzzy MCDM models.

The first group of papers introduces how to apply aggregations operators such as the OWA operators and Heronian Mean in the development of new fuzzy MCDM models:

- Vizuete-Luciano et al. in "Decision making in the assignment process by using the Hungarian algorithm with OWA operators" present the Hungarian method that is a combinatorial optimization algorithm that solves the assignment problem in polynomial time. Authors introduce a new approach of the Hungarian method based on the famous Ordered Weighting Averaging operators introduced by Ronald Yager. They also show how this new approach could be used in a financial decision making problem regarding the assignment of investments.

- In the paper entitled "Some Heronian mean operators with 2-tuple linguistic information and their application to multiple attribute group decision making", by Li and Liu, new fuzzy linguistic approaches of the Heronian mean operator are defined by assuming that the user preferences are modelled by means of linguistic variables. To do that, they use a linguistic 2-tuple preference modelling. Authors propose some new 2-tuple generalized Heronian mean operators, which can process the interactions between the attributes. They also show their application in multi-attribute decisionmaking problems.

The second group of contributions includes tools to deal with weights in fuzzy MCDM models, modelling the importance of criteria and, specially, by incorporating the influence of time factor in fuzzy decision-making contexts.

- Razavi Hajiagha et al. in "Determining weights of fuzzy attributes for multi-attribute decision-making problems based on consensus of expert opinions" introduce a new approach for fuzzy multi-attribute group decision-making problems defined in heterogeneous contexts. In such a way, they assume that decision makers' opinions on attributes are not equally important. By assuming that the opinions are expressed by means of fuzzy numbers, they introduce a new method to derive decision makers' weights whose main advantage is the possibility of computing different weights for each decision maker in different attributes.

- Li et al. in "Dynamic fuzzy multiple criteria decision making for performance evaluation" provide a new dynamic fuzzy MCDM method defined in a heterogeneous context and by considering the effect of time in the decision making process. In such a way, an interesting dynamic MCDM approach is presented. In this new MCDM approach, on the one hand, integrated weights for the attributes are computed from expert preferences by combining objective and subjective methods. On the other hand, the influence of the time factor is also considered.

The last group of contributions includes applications covering different application fields as the selection of leisure space in urban areas, selection of hydro-power plant projects, selection of projects in telecommunication companies, and production problems in companies. 
- The first paper of this group by Pourahmad et al. "Combination of fuzzy-AHP and DEMATEL-ANP with GIS in a new hybrid MCDM model used for the selection of the best space for leisure in a blighted urban site", presents a new hybrid fuzzy MCDM approach to solve the problem of selection of appropriate locations as leisure spaces in urban areas. This innovative approach combines different decision making tools as Fuzzy-AHP, ANP, and DEMATEL together with GIS tools. Authors show how it could be applied in the identification of the appropriate locations for leisure spaces development in Gheytariyeh neighborhood of Tehran.

- In the paper entitled "Small hydro-power plant project selection using fuzzy axiomatic design principles", by Khandekar et al. a rational fuzzy MCDM methodology is proposed in order to assist a developer in selecting the most profitable and feasible small hydro-power plant project for construction and subsequent operation. The techno-commercial and socio-economic criteria as considered for analyzing the feasibility of the candidate projects. The preferences are expressed qualitatively using trapezoidal fuzzy numbers. An example of selection of four projects of $25 \mathrm{MW}$ generation capacity to be located at different geographical sites in India is presented.

- Cid-López et al. in "A hybrid model for decision-making in the Information and Communications Technology sector" propose a fuzzy hybrid MCDM model based on a 2-tuple linguistic modelling. This new approach allows us to make decisions according to both, the expert opinions and an intelligent information system that plays the role of a virtual expert. To validate the model presented, a specific example of decision-making in a telecommunication company in relation to a problem in its commercial area that was affecting the company's image is presented.

- Stanojević et al. in "On the ratio of fuzzy numbers - exact membership function computation and applications to decision making" present a new approach to solving the full fuzzy linear fractional programming problem by using the $\alpha$-cut interval of a special class of fuzzy numbers. They show how it is possible to use such proposal in decision making for production problems of companies when we have to determine the optimal number of units to produce for each product per week.

\section{References}

Alonso, S.; Chiclana, F.; Herrera, F.; Herrera-Viedma, E.; Alcalá, J.; Porcel, C. 2008. A consistency based procedure to estimate missing pairwise preference values, International Journal of Intelligent Systems 23(2): 155-175. http://dx.doi.org/10.1002/int.20262

Alonso, S.; Pérez, I. J.; Cabrerizo, F. J.; Herrera-Viedma, E. 2013. A linguistic consensus model for web 2.0 communities, Applied Soft Computing 13(1): 149-157. http://dx.doi.org/10.1016/j.asoc.2012.08.009

Bellman, R.; Zadeh, L. A. 1970. Decision making in a fuzzy environment, Management Science 17(4): 141-164. http://dx.doi.org/10.1287/mnsc.17.4.B141

Buckley, J. J. ; Eslami, E. ; Feuring, T. 2002. Fuzzy mathematics in economics and engineering. PhysicaVerlag. http://dx.doi.org/10.1007/978-3-7908-1795-9

Brans, J. P.; Vincke, Ph. 1985. A Preference ranking organization method (The Promethee method for multiple criteria decision making), Management Science 31: 647-656.

http://dx.doi.org/10.1287/mnsc.31.6.647 
Carlsson, C.; Fuller, R. 1996. Fuzzy multiple criteria decision making: recent developments, Fuzzy Sets and Systems 78(2): 139-153. http://dx.doi.org/10.1016/0165-0114(95)00165-4

Cabrerizo, F. J.; Chiclana, F.; Al-Hmouz, R.; Morfeq, A.; Balamash, A. S.; Herrera-Viedma, E. 2015. Fuzzy decision making and consensus: challenges, Journal of Intelligent \& Fuzzy Systems (in press). http://dx.doi.org/10.3233/IFS-151719

Cabrerizo, F. J.; Moreno, J. M.; Pérez, I. J.; Herrera-Viedma, E. 2010. Analyzing consensus approaches in fuzzy group decision making: advantages and drawbacks, Soft Computing 14(5): 451-463. http://dx.doi.org/10.1007/s00500-009-0453-x

Delgado, M.; Kacprzyk, J.; Verdegay, J. L.; Vila, M. A. (Eds.) 1994. Fuzzy optimization. Recent advances. Physica-Verlag.

Dubois, D.; Prade, H. 1988. Fuzzy sets and systems. New York: Academic Press.

Fishburn, P. C. 1970. Utility theory for decision making. New York: Wiley.

Fodor, J.; Roubens, M. 1994. Fuzzy preference modelling and multicriteria decision support. Boston: Kluwer Academic Publishers. http://dx.doi.org/10.1007/978-94-017-1648-2

Herrera-Viedma, E.; Crestani, F.; Pasi, G. 2006. Soft computing for Web information retrieval. Heidelberg: Physica Verlag. http://dx.doi.org/10.1007/3-540-31590-X

Kacprzyk, J.; Pedrycz, W. (Eds.) 2015. Handbook of computational intelligence. Dordrecht: Springer. http://dx.doi.org/10.1007/978-3-662-43505-2

Kacprzyk, J.; Nurmi, H.; Fedrizzi, M. 1997. Consensus under fuzziness. Boston: Kluwer Academics Publishers. http://dx.doi.org/10.1007/978-1-4615-6333-4

Kaufmann, A.; Gupta, M. M. 1988. Fuzzy mathematical models in engineering and management science. Amsterdam.

Keeney, R. L.; Raiffa, H. 1976. Decisions with multiple objectives: preferences and value tradeoffs. New York: Wiley.

Klir, G. J.; Yuan, G. 1995. Fuzzy sets and fuzzy logic: theory and applications. New York: Prentice Hall.

Lehrer, K.; Wagner, C. 1981. Rational consensus in science and society: a philosophical and mathematical study. Springer. http://dx.doi.org/10.1007/978-94-009-8520-9

Massanet, S.; Riera, J. V.; Torrens, J.; Herrera-Viedma, E. 2014. A new linguistic computational model based on discrete fuzzy numbers for computing with words, Information Sciences 258: 277-290. http://dx.doi.org/10.1016/j.ins.2013.06.055

Morente-Molinera, J. A.; Perez, I. J.; Ureña, R.; Herrera-Viedma, E. 2015. On multi-granular fuzzy linguistic modelling in group decision making problems: a systematic review and future trends, Knowledge Based Systems 74: 49-60. http://dx.doi.org/10.1016/j.knosys.2014.11.001

Pérez, I. J.; Cabrerizo, F. J.; Herrera-Viedma, E. 2010. A mobile decision support system for dynamic group decision-making problems, IEEE Transactions on Systems, Man, and Cybernetics - Part A: Systems and Humans 40(6): 1244-1256. http://dx.doi.org/10.1109/TSMCA.2010.2046732

Pérez, I. J.; Cabrerizo, F. J.; Alonso, S.; Herrera-Viedma, E. 2014. A new consensus model for group decision making problems with non homogeneous experts, IEEE Transactions on Systems, Man, and Cybernetics: Systems 44(4): 494-498. http://dx.doi.org/10.1109/TSMC.2013.2259155

Roy, B. 1968. Classement et choix en présence de points de vue multiples (la méthode ELECTRE), La Revue d'Informatique et de Recherche Opérationelle (RIRO) 8: 57-75.

Saaty, T. L. 1980. The analytical hierarchy process. New York: McGraw Hill.

Ureña, R.; Chiclana, F.; Morente-Molinera, J. A.; Herrera-Viedma, E. 2015. Managing incomplete preference relations in decision making: a review and future trends, Information Sciences 302: 14-32. http://dx.doi.org/10.1016/j.ins.2014.12.061 
Wu, J.; Chiclana, F.; Herrera-Viedma, E. 2015. Trust based consensus model for social network in an incomplete linguistic information context, Applied Soft Computing (in press). http://dx.doi.org/10.1016/j.asoc.2015.02.023

Yager, R. R.; Zadeh, L. A. (Eds.) 1992. An introduction to fuzzy logic applications in intelligent systems. Boston: Kluwer Academic Publisher. http://dx.doi.org/10.1007/978-1-4615-3640-6

Yu, P. L. 1973. A class of solutions for group decision problems, Management Science 19(8): 936-946. http://dx.doi.org/10.1287/mnsc.19.8.936

Zadeh, L. A. 1965. Fuzzy sets, Information and Control 8(3): 338-353. http://dx.doi.org/10.1016/S0019-9958(65)90241-X

Zadeh, L. A. 1975a. The concept of a linguistic variable and its applications to approximate reasoning. Part I, Information Sciences 8(3): 199-243. http://dx.doi.org/10.1016/0020-0255(75)90036-5

Zadeh, L. A. 1975b. The concept of a linguistic variable and its applications to approximate reasoning. Part II, Information Sciences 8(4): 301-357. http://dx.doi.org/10.1016/0020-0255(75)90046-8

Zadeh, L. A. 1975c. The concept of a linguistic variable and its application to approximate reasoning: Part III, Information Sciences 9(1): 43-80. http://dx.doi.org/10.1016/0020-0255(75)90017-1

Zartman, W. I. 1978. The negotiation process: theories and applications. Beverly Hills: Sage.

Zeleny, M. 1973. Compromise programming, in J. L. Cochrane, M. Zeleny (Eds.). Multiple criteria decision making. Columbia: Carolina Press.

Zimmermann, H. J. 1987. Fuzzy sets, decision-making and expert systems. Boston: Kluwer Academic Publisher. http://dx.doi.org/10.1007/978-94-009-3249-4

Zopounidis, C.; Pardalos, P. M.; Baourakis, G. 2001. Fuzzy sets in management, economics, and marketing. World Scientific. 